\title{
Intimate partner violence against pregnant women in East Gojjam Zone, Ethiopia
}

Lalem Menber Belay ( $\square$ lalemph@gmail.com )

JHPIEGO

Nigist Menber

Alkan Medical College

Research article

Keywords: Prevalence, intimate partner violence, married women, Ethiopia

Posted Date: September 11th, 2019

DOI: https://doi.org/10.21203/rs.2.14280/v1

License: (9) This work is licensed under a Creative Commons Attribution 4.0 International License. Read Full License 


\section{Abstract}

\section{Abstract}

Background: Though underestimated, intimate partner violence (IPV) against women in Ethiopia is among the highest in the world. The overall aim of the study was to assess the prevalence and forms of intimate partner violence during pregnancy, associated factors, and recommendations to reduce the act.

Methods: A cross-sectional study was conducted from January 25 to February 15, 2018 in government health facilities, North West Ethiopia. Married women who seek antenatal care service were participated in the study. Ethical clearance and approval was obtained from Amhara Regional Health Bureau research and publication committee. Informed consent was obtained from women and facility managers before collecting the data. Odds ratio (OR) with $95 \% \mathrm{Cl}$ was computed to determine the presence and strength of association between the outcome of interest and key independent variables.

Results: Nearly half (46.4\%) of the study participants were victims of at least one episodes of intimate partner violence in the recent pregnancy. Psychological violence 141 (44.2\%) was the most common form of violence encountered followed by sexual violence 137 (42.9\%). Significant proportion of women were insulted, forced to have sex, pushed/shoved, kicked/beaten, and slapped/thrown something at them (30.1 - 39.4\%) in the recent pregnancy. Lack of formal education, arranged marriages, lack of decisionmaking autonomy in household matters and wider spousal age difference were significantly associated with intimate partner violence.

Conclusions: Higher proportion of pregnant women experienced intimate partner violence. Sociodemographic factors were associated with intimate partner violence. We suggest interventions focusing on education for raising community awareness through different strategies. Strengthening health facilities is also important to early identify and manage pregnant women with intimate partner violence, and prevent adverse birth outcomes of the act.

\section{Background}

Violence against women is a global public health concern and affects everyone in the world[1, 2]. Globally, one-third of women experienced some form of physical, psychological/emotional and/or sexual violence [2]. The prevalence of the act is wider in Africa, Middle East and Latin America [3]. World Health Organization's (WHO's) multi-country study revealed that Japanese women experienced the lowest rates of domestic violence while the highest is in Ethiopia, Peru, and Bangladesh. [1] Studies showed that the prevalence of IPV was 30.3\% in Tanzania, 53.2\% in Nepal, and 67\% in Kenya [4-6]. A systemic review of African studies showed that intimate partner violence during pregnancy ranged from $2.3 \%$ to $57.1 \%$; most of the studies showed a prevalence of $27 \%$ and above [7].

Violence against pregnant women results in fatal and non-fatal health outcomes for the mother and her baby $[8,9]$. The adverse health outcomes of IPV during pregnancy is higher in women with low socio 
economic status [9]. Adjusted for socioeconomic status of women, IPV was associated with depressive episodes in women[10]. The period of pregnancy by itself is stressful due to many uncertainties associated with it. Moreover, pregnant women are not immune for IPV; the violence may begin or worsen during pregnancy. The level of stress during pregnancy affects the severity of birth outcome [3]. Women experiencing IPV are predisposed to medical, gynaecological, and mental health problems [11]. IPV results in anxiety, depression, and stress which may lead to a higher risk of adverse obstetric outcomes; hypertension, anaemia, premature rupture of membrane, preterm delivery, low birth weight, vaginal bleeding, urinary tract infection, vomiting and dehydration, and low APGAR scores of 1 \& 5 minutes. A mother with stress will have abnormally high level of cortisol and adrenaline in her blood. This high level of stress hormones will reach the baby and affect the baby's brain development. It also cause changes in the blood flow to the baby, making it difficult to carry oxygen and other important nutrients to the baby's developing organs, and make the mothers feel overwhelmed and fatigued which might impact their diet and sleep habits and consistency of prenatal care. $[3,12,13]$

Despite the due attention given by the Ethiopian government for the protection of women's' right, $20 \%$ to $78 \%$ of women experienced lifetime domestic violence by their husband or intimate partner [14-17]. In Ethiopia, there is a deep-rooted traditional norm that supports men to discipline their wives in which wife beating is considered as normal [18]. Furthermore, IPV is often protected by family secrecy, cultural norms, fear, shame, community's reluctance on domestic affair and social stigma made the women remain silent, only few defend themselves[19]. As a result, evidence on the magnitude of IPV during pregnancy and its effect on adverse birth outcomes is scarce [20]. Therefore, the purpose of this study was to assess the magnitude of IPV against pregnant women and key factors associated with the act.

\section{Methods}

A cross-sectional study was conducted on pregnant women in East Gojjam Zone, Machakel woreda in government health facilities. The woreda is located in North West Ethiopia, 330 kilometers from the capital, Addis Ababa. The study lasted from January 25 to February 15, 2018. There are 31 health facilities ( 6 health centers and 25 health posts) in the Woreda. The woreda is dominantly rural with a population of 118,097 and a total area of 746.43 square kilometre.

All married /cohabited pregnant women who seek ANC service at health centres were included in the sample. We recruited women from six health centres who visited the health centres during the study period. The sample size has been estimated to be 319. It was determined using single population proportion formula $n=[D E F F * N p(1-p)] /\left[\left(d^{2} / Z^{2}{ }_{1-a / 2} *(N-1)+p *(1-p)\right]\right.$ based on the following assumptions: $72.5 \%$ past 12 months prevalence of intimate violence in Ethiopia[17], $5 \%$ tolerable errors, $95 \%$ level of confidence and $10 \%$ non-response rate. All women who fulfil the inclusion criteria and come to the health centre during the study period were included. Based on the client flow one month before the data collection period, proportional allocation of the total sample size was done to get the required sample from each health centre. 
Trained health extension workers collected the data by face-to-face interview using structured and pretested questionnaire adopted from WHO multi-country study on women's health and domestic violence against women[21]. The interview was conducted privately in a separate room. Ethical clearance and approval was obtained from Research and Publications Committee of Amhara Regional Health Bureau. Support letter was written to the health centres. Women were informed about the objective, procedures, potential risks and benefits of the study and written consent was obtained before the interview. STATA IC 12.1 software used for statistical analysis. Odds ratio with $95 \% \mathrm{Cl}$ computed to determine the presence and strength of associated factors with IPV

\section{Results}

\section{Socio-demographic and behavioural characteristics of study participants}

Three hundred and nineteen pregnant women from six health centres participated in the study; yielding a response rate of $100 \%$. Two hundred twenty three $(69.9 \%)$ of women were below the age 30 years old andthe mean age of women was 28 years $(28.2 \pm 4.5 \mathrm{SD})$. significant proportion of participants 127 (39.8\%) married at the age of below 15 years old. On average, a woman have four children (4.0 $\pm 2.6 \mathrm{SD})$. Majority of women were rural residents $288(90.7 \%)$, farmer by occupation $233(72.7 \%)$, have no formal education 256 (80.3\%), lived for more than 10 years with the current husband 216(67.7\%) and lived in a family in which husband making decision alone 189 (59.2\%). Families and or relatives arranged most of the marriages $287(90.0 \%)$ which was not based on their choice.

\section{Table 1: Socio demographic and behavioural characteristic of women and their husbands/partners, Ethiopia, 2018}




\begin{tabular}{lcc}
\hline Variables & Frequency & Percent \\
\hline Residence & & \\
Rural & 288 & 90.7 \\
\hline Urban & 29 & 9.3 \\
\hline Age of the women (in years) & & \\
\hline $15-24$ & 141 & 44.2 \\
\hline $25-34$ & 144 & 45.1 \\
\hline$\geq 35$ & 34 & 10.7 \\
\hline Occupation of the woman & & \\
\hline Farmer & 233 & 72.7 \\
\hline House wife & 78 & 24.8 \\
\hline Others & 8 & 2.5 \\
\hline Educational status of the woman & & \\
\hline No formal education & 256 & 80.3 \\
\hline Primary education and above & 62 & 19.5 \\
\hline Marital life (in years) & & \\
\hline$<5$ & 55 & 17.2 \\
\hline $5-9$ & 48 & 15.0 \\
\hline $10-14$ & 54 & 16.9 \\
\hline$\geq 15$ & 162 & 50.8 \\
\hline Age of woman at first marriage (in years) & & \\
\hline$<10$ & 31 & 9.7 \\
\hline $10-14$ & 96 & 30.1 \\
\hline $15-19$ & 154 & 48.4 \\
\hline$\geq 20$ & 38 & 11.8 \\
\hline Number of children & & \\
\hline$\leq 4$ & & \\
\hline$\geq 5$ & & \\
\hline Do families / relatives arrange the marriage? & & \\
\hline Yes & & \\
\hline No & & \\
\hline & & \\
\hline
\end{tabular}

\section{Partner's characteristics}

Ninety-four (29.5\%) of the husbands were above 50 years of age and significant majority of them 206 $(64.6 \%)$ were older than their wives by 5 years or more. Most of the husbands $218(68.3 \%)$ have no formal education, drink alcohol which is locally made beverage called 'tella' $285(89.3 \%)$ and have decision making autonomy in household matters 189 (59.2\%). 


\section{Table 2: Socio demographic characteristic of the husbands/partners, Ethiopia, 2018}

\begin{tabular}{lcc}
\hline Variables & Frequency & Percent \\
\hline Age of the husband (years) & 10 & 3.2 \\
\hline $15-24$ & 76 & 23.8 \\
\hline $25-34$ & 105 & 32.9 \\
\hline $35-44$ & 128 & 40.1 \\
\hline$\geq 45$ & & \\
\hline Educational status of the husband & 218 & 68.3 \\
\hline No formal education & 101 & 31.7 \\
\hline Primary education and above & & \\
\hline Do the partner practice extramarital sex? & 29 & 9.1 \\
\hline Yes & 290 & 90.9 \\
\hline No & & \\
\hline Do partner / husband drink alcohol? & 285 & 89.3 \\
\hline Yes & 34 & 10.7 \\
\hline No & & \\
\hline Decision making autonomy & 28 & 8.8 \\
\hline Female & 189 & 59.2 \\
\hline Male & 102 & 32.0 \\
\hline Both & & \\
\hline Spousal age difference & 113 & 35.4 \\
\hline Husband 0-4 years older than wife & 146 & 45.8 \\
\hline Husband 5-9 years older than wife & 45 & 14.1 \\
\hline Husband10-14 years older than wife & 15 & 4.7 \\
\hline Husband $\geq 15$ years older than wife & & \\
\hline
\end{tabular}

\section{Prevalence and forms intimate partner violence during pregnancy}

In this study, we assessed the prevalence of all forms of intimate partner violence during the current pregnancy (psychological, physical, and sexual). The proportion of women who experienced at least one episodes of intimate partner violence during the current pregnancy was $148(46.4 \%)$.

\section{Psychological violence}

Psychological violence was the most common form of violence experienced by women 141 (44.2\%). More than one-third (35.6\%) of the women were verbally insulted by their husband in the current 
pregnancy. In addition, a quarter of the women were humiliated in front of others and threatened or

frightened by their husband. Moreover, their husband intimidated one in three women on purpose.

\section{Physical violence}

Forty-one percent of pregnant women experienced at least one episode of physical violence (slapped, pushed, hit with fist, kicked/beaten, choked or threatened with some form of weapon) in the recent pregnancy. Significant proportion of women $(37.6 \%)$ experienced severe forms of physical violence; was hit with fist or beaten with something else that could hurt the woman, kicked or dragged. Moreover, other severe forms of physical violence like choking and threatening with gun or knife were also common.

\section{Sexual/emotional violence}

About $43 \%$ of women in the current pregnancy encountered sexual violence. About forty percent of women, their husband forced to have sex without their interest. Besides, $32.5 \%$ of women had sexual intercourse during the current pregnancy due to fear of what the husband might do. Furthermore, $6.5 \%$ of women, their husband forced into a sexual practice that the woman found it humiliating and out of their norms. (Table 2)

\section{Table 3: Forms of intimate partner violence against women during pregnancy, Ethiopia, 2018}


Psychological/Emotional violence

Insulted/made feel bad

35.6

Humiliated in front of others

114

26.8

Intimidated on purpose

85

30.1

Threatened/hurt/frightened

96

23.3

Experienced at least one episodes of psychological / emotional violence

74

44.2

Physical violence

Slapped/Thrown something

141

Pushed or shoved

126

39.4

Hit with fist or something else

107

33.6

Kicked, dragged or beat

120

37.6

Choked or burnt

120

37.6

Threatened or used weapon (gun, knife)

30

9.3

Experienced at least one episodes of physical violence

26

8.1

Sexual violence

Physically forced to have sex

132

41.5

Having sex because of fear of partner

129

40.3

Sex that is degrading/humiliating

104

32.6

Experienced at least one episodes of sexual violence

21

6.5

All forms of IPV

\section{Discussion}

Intimate partner violence against pregnant women though underestimated; it has serious health consequences for the mother and the baby. The current study aimed to assess the prevalence and forms of IPV during pregnancy, factors associated with it and forward recommendations to reduce the act in the study area.

The overall prevalence of all forms of IPV against women (psychological, physical and sexual) during the recent pregnancy was unacceptably high. Nearly half of the study participants encountered at least one episodes of IPV in the recent pregnancy. The result of the current study (46.4\%) was comparable with findings of a study done in Debre Markos, Ethiopia (41.1\%) [22] and cape town, South Africa (44\%) [23],but lower compared to findings from Bale zone, Ethiopia(59.0\%)[24], Abay Chomen district, Ethiopia (55.5\%) [20] and Kenya (66.9\%) [4]. The difference could be explained by socio-cultural differences in the study populations. Furthermore, the prevalence of IPV in this study was lower than the lifetime prevalence of IPV in Ethiopia (60.6\%), and low and lower-middle income countries $(55.8 \%)[15,16]$.

In contrast, the finding of the current study was higher than a study done in South Africa (15\%)[25]and Tanzania (30.3\%) [5]. The likelihood of IPV against Ethiopia women was three fold of the rate in South 
Africa [25]. Similarly, Ethiopian women were victims of IPV at a rate of $16 \%$ higher than Tanzanian women were [5]. The possible explanations for the high prevalence of IPV in the current study could be explained by differences in socioeconomic status and the presence of deep rooted traditional norms that support wife beating as the rights of men to discipline their wives [26]. Being dominantly rural, such traditional norms are common and accepted in the community. Thought no statistical significant association observed, higher proportion of rural women encountered IPV.

Regarding factors associated with IPV, women's and husband's educational status, women's age (25 to 34 years), decision-making autonomy in household matters, marriages arranged by families and or relatives and spousal age difference were significantly associated with IPV. The prevalence of IPV was lowest among women of age 35 years and above, lack formal education or married to a man with no formal education, lack decision-making autonomy in household matters, had wider spousal age difference, and had no role to choose their partner. However, residence, occupation of the women, number of children and marital life were not associated with IPV perpetration. (Table 4)

In this study, women 35 years of age and above were $70 \%(\mathrm{COR}=0.3,95 \% \mathrm{Cl} ; 0.1,0.8)$ less likely to encounter IPV compared to young adults (15 to 24 years of age). This finding is comparable with a findings from other studies; the probability of IPV perpetration is higher among adolescents and decreases starting in the late twenties [11,27].

The study corroborated that educational literacy has an inverse relation with IPV perpetration. Educational status of the woman and her husband was significantly associated with IPV among pregnant women. Women who had no formal education experienced IPV 7 times (COR $=7.0,95 \% \mathrm{Cl}$; 3.1, 17.8) the rate of IPV among women who attended primary education or above. Similarly, women married to an illiterate husband had a 3 times increased risk of experiencing IPV compared to those married to men who attended primary education or above. This finding was supported by other studies done in Ethiopia [15,28] and Kenya [4]. The possible explanation can be, when individuals and community got educated, they will have knowledge on human rights and skills to negotiate and solve disagreements through discussion. Interventions to improve awareness of couples through different approaches will help to prevent and reduce the occurrence of violence against women.

This study also found that arranged marriage was significantly associated with the likelihood of intimate partner violence during pregnancy. Marriage unions arranged by families and or relatives had $300 \%$ (COR $=2.8,95 \% \mathrm{Cl} ; 1.2,7.6)$ increased likelihood of IPV perpetration as compared to those unions happened by choice. The possible explanation could be romantic relationships may not be common among couples whose marriages are arranged by families and or relatives. Especially it will be true in the early life of the marriage until the couples develop truest and commitment. Arranged marriage is a common social phenomenon in the study area. Typically, the father/ family of the prospective groom will send elders to the father/family of the prospective bride to propose a marriage. If the union is acceptable, the families will negotiate the marital exchange and set the wedding date[29]. Besides, most women got married at an early age, below 15 years old without their choice. When women got married at early, they age are 
disadvantaged within the marriage. They enter marriage without adequate knowledge and skills to negotiate marital roles [29].

Our study showed that wider spousal age difference was associated with IPV perpetration. Women who had age difference of 10 years or more with their spouses experienced 3 times $(\mathrm{COR}=2.9,95 \% \mathrm{Cl} ; 1.4$, 5.9) higher rate of IPV compared to those who had less than 5 years age difference. The finding emphasizes the need for couples to have same level of maturity and understanding. However, a study done in Nigeria and a meta-analysis on the association between IPV and spousal age showed that IPV perpetration reduced with increased spousal age difference [30,31]. The disagreement in the findings needs further study.

Findings of this study also showed that decision-making autonomy is an important factor associated with lower likelihood of IPV. The likelihood of IPV perpetration was higher in families where husband is making decision alone compared to woman alone. Husband making decision alone in household matters had a seven times $(\mathrm{COR}=6.7,95 \% \mathrm{Cl}, 2.3,23.3)$ increased likelihood of IPV perpetration compared to woman decision-making alone. Other studies in Ethiopia substantiated the finding [15]. Similarly, a study in Uganda showed that women decision making in large household purchases and expenditure of husband's earnings was associated with lower probability of IPV. However, unlike the current study women's reporting decision-making autonomy was not significantly associated with IPV. [32].

\section{Table 4: Intimate partner violence during pregnancy by socio- demographic and behavioural characteristics, Ethiopia, 2018}




\begin{tabular}{|c|c|c|c|}
\hline Variables & IPV exposed & IPV non-exposed & COR $(95 \% \mathrm{Cl})$ \\
\hline \multicolumn{4}{|l|}{ Residence } \\
\hline Rural & 130 & 160 & $0.5(0.2,1.2)$ \\
\hline Urban & 18 & 11 & ref \\
\hline \multicolumn{4}{|l|}{ Age of the women } \\
\hline $15-24$ & 64 & 77 & ref \\
\hline $25-34$ & 77 & 67 & $1.4(0.8,2.3)$ \\
\hline$\geq 35$ & 7 & 27 & $0.3(0.1,0.8)$ \\
\hline \multicolumn{4}{|l|}{ Occupation of the women } \\
\hline Farmer & 111 & 121 & ref \\
\hline House wife & 35 & 44 & $0.9(0.5,1.5)$ \\
\hline $\begin{array}{l}\text { Others (government employee, merchant, daily } \\
\text { labour) }\end{array}$ & 2 & 6 & $0.4(0.0,2.1)$ \\
\hline \multicolumn{4}{|l|}{ Marital life (in years) } \\
\hline$<5$ & 24 & 31 & ref \\
\hline $5-10$ & 28 & 20 & $1.9(0.8,4.5)$ \\
\hline $11-15$ & 22 & 32 & $0.9(0.4,2.2)$ \\
\hline$>15$ & 74 & 88 & $1.2(0.6,2.2)$ \\
\hline \multicolumn{4}{|l|}{ Educational status of the women } \\
\hline No formal education & 140 & 122 & $7.0(3.1,17.8)$ \\
\hline Primary education and above & 8 & 49 & ref \\
\hline \multicolumn{4}{|l|}{ Age difference with the spouse (in years) } \\
\hline$<5$ & 44 & 69 & ref \\
\hline $5-10$ & 65 & 81 & $1.3(0.7,2.1)$ \\
\hline$>10$ & 39 & 21 & $2.9(1.4,5.9)$ \\
\hline \multicolumn{4}{|l|}{ Number of children } \\
\hline$\leq 4$ & 76 & 104 & ref \\
\hline$\geq 5$ & 72 & 67 & $1.5(0.9,2.4)$ \\
\hline \multicolumn{4}{|l|}{ Decision making role in the house hold } \\
\hline Women & 5 & 23 & ref \\
\hline Man & 112 & 77 & $6.7(2.3,23.3)$ \\
\hline Both & 31 & 71 & $2.0(0.7,7.4)$ \\
\hline \multicolumn{4}{|l|}{ Did families / relatives arrange the marriage? } \\
\hline Yes & 140 & 147 & $2.8(1.2,7.6)$ \\
\hline No & 8 & 24 & ref \\
\hline \multicolumn{4}{|l|}{ Educational status of the husband } \\
\hline No formal education & 118 & 100 & $2.8(1.6,4.8)$ \\
\hline Primary education and above & 30 & 71 & ref \\
\hline
\end{tabular}




\section{Limitations Of The Study}

In this study, the prevalence of IPV was determined based on the reports of women and social desirability bias might affect the result. In addition, we could not able to compute multivariate analysis due the insufficiency of samples in each category of a variable. Therefore, the observed associations might have been confounded.

\section{Conclusions}

The prevalence of intimate partner violence during pregnancy in Machakel woreda, is relatively high. Nearly half of the pregnant women experienced at least one form of intimate partner violence by their husband. The problem seems to be more common among women age 25 to 29 years old, couples having wider spousal age difference, women with no formal education or married to a man with no formal education, women with low or no decision-making power in house hold matters and marriages arranged by families and or relatives. Findings suggest that interventions focused on education and awareness creation activities through various approaches may be protective against IPV. Health facilities should be strengthened to do health education and community awareness activities, identify and counsel and or link pregnant women with intimate partner violence.

\section{Abbreviations}

ANC

Antenatal Care

APGAR

Appearance, Pulse, Grimace, Activity and Respiration

$\mathrm{Cl}$

Confidence Interval

COR

Crude Odds Ratio

DEFF

Design Effect

iNGO

International Non-Governmental Organizations 
IPV

Intimate Partner Violence

SD

Standard Deviation

WHO

World Health organization

\section{Declarations}

\section{Ethics approval and consent to participate}

The study got ethical approval from Research and Publications Committee of Amhara Regional Health Bureau and support letter was written to the study sites. Data was collected after informed written consent was obtained from study participants. For women of age less than 18 years old informed written consent was obtained from accompanies (husband, parent). The purpose of the study and the time needed to conduct the interview was explained to the study participants. Confidentiality of the data was ensured and there was no personal identifier attached to the questionnaire.

\section{Consent for publication}

The author representing all the authors grants the publisher a full copyright license to publish in whole or part without limitation in all forms of media.

\section{Availability of data and material}

The dataset used and/or analysed for the current study is available from the corresponding author on request.

\section{Competing interest}

No competing or conflict of interest to declare.

\section{Funding}

No funding was obtained for this study 


\section{Author's contribution}

LMB conceived and designed the study, performed analysis and interpretation, and prepare and review the manuscript. NM participated in the design of the study, data analysis and interpretation and reviewed the manuscript. All authors read and approved the final manuscript.

\section{Author details}

${ }^{1}$ Health workforce improvement program, iNGO, P. O.Box 1556, Bahir Dar, Ethiopia

${ }^{2}$ Alkan Medical College, Bahir Dar, Ethiopia

\section{Acknowledgements}

We would like to thank the Amhara Regional Health Bureau for giving the opportunity to conduct this study. We are also grateful for mothers who participated in this study.

\section{References}

1.Garcia-Moreno C, Jansen HA, Ellsberg M, Heise L, Watts PCH: Prevalence of intimate partner violence: findings from the WHO multi-country study on women's health and domestic violence. THE LANCET 2006, 368(9543).

2.WHO: Violence againest women: key facts. In., November 29, 2017 edn; 2017.

3.Cook J, Bewley S: Acknowledging a persistent truth: domestic violence in pregnancy. Journal of the Royal Society of Medicine 2008, 101(7):358-363.

4.Owaka IO, Nyanchoka MK, Atieli HE: Intimate partner violence in pregnancy among antenatal attendees at health facilities in West Pokot county, Kenya. The Pan African medical journal 2017, 28:229.

5.Sigalla GN, Mushi D, Meyrowitsch DW, Manongi R, Rogathi JJ, Gammeltoft T, Rasch V: Intimate partner violence during pregnancy and its association with preterm birth and low birth weight in Tanzania: $A$ prospective cohort study. PloS one 2017, 12(2):e0172540.

6.Regmi MC, Subedi L, Shrestha R, Dixit B, Shrestha N: Prevalence of domestic violence among the prgnant women attending BPKIHS. NJOG 2017, 12(1):32-35.

7.Shamu S, Abrahams N, Temmerman M, Musekiwa A, Zarowsky C: A systematic review of African studies on intimate partner violence against pregnant women: prevalence and risk factors. PloS one 2011, 6(3):e17591. 
8.Dahlen HG, Munoz AM, Schmied V, Thornton C: The relationship between intimate partner violence reported at the first antenatal booking visit and obstetric and perinatal outcomes in an ethnically diverse group of Australian pregnant women: a population-based study over 10 years. BMJ Open 2018, 8(4):e019566.

9.Alhusen JL, Bullock L, Sharps P, Schminkey D, Comstock E, Campbell J: Intimate partner violence during pregnancy and adverse neonatal outcomes in low-income women. Journal of women's health (2002) 2014, 23(11):920-926.

10.Deyessa N, Berhane Y, Alem A, Ellsberg M, Emmelin M, Hogberg U, Kullgren G: Intimate partner violence and depression among women in rural Ethiopia: a cross-sectional study. Clinical Practice and Epidemiology in Mental Health 2009, 5(1):8.

11.Miller E, McCaw B: Intimate Partner Violence. N Engl J Med 2019, 380(9):850-857.

12.Bekele I, Demeke T, Dugna K: Prevalence of Preterm Birth and its Associated Factors among Mothers Delivered in Jimma University Specialized Teaching and Referral Hospital, Jimma Zone, Oromia Regional State, South West Ethiopia. Women's health 2017, 6(1).

13.Gebreslasie K: Preterm Birth and Associated Factors among Mothers Who Gave Birth in Gondar Town Health Institutions. Advances in Nursing 2016.

14.Abeya SG, Afework MF, Yalew AW: Intimate partner violence against women in west Ethiopia: a qualitative study on attitudes, woman's response, and suggested measures as perceived by community members. Reproductive Health 2012.

15.Semahegn A, Mengistie B: Domestic violence against women and associated factors in Ethiopia; systematic review. Reproductive health 2015, $12: 78$.

16.Semahegn A, Torpey K, Manu A, Assefa N, Tesfaye G, Ankomah A: Are interventions focused on gender-norms effective in preventing domestic violence against women in low and lower-middle income countries? A systematic review and meta-analysis. Reproductive health 2019, 16(1):93.

17.Abeya SG, Afework MF, Yalew AW: Intimate partner violence against women in western Ethiopia: prevalence, patterns, and associated factors. BMC Public Health 2011, 11(1):913.

18.Gurmu E, Endale S: Wife beating refusal among women of reproductive age in urban and rural Ethiopia. BMC international health and human rights 2017, 17(1):6.

19.Abeya SG, Afework MF, Yalew AW: Intimate partner violence against women in west Ethiopia: a qualitative study on attitudes, woman's response, and suggested measures as perceived by community members. Reproductive health 2012, 9(1):14. 
20.Abebe Abate B, Admassu Wossen B, Tilahun Degfie T: Determinants of intimate partner violence during pregnancy among married women in Abay Chomen district, Western Ethiopia: a community based cross sectional study. BMC women's health 2016, 16:16.

21.Claudia Garcia-Moreno, Henrica F. F. M. Jansen, Ellsberg. M, Watts. C: WHO Multi-country Study on Women's Health and Domestic Violence against Women. 2005.

22.Azene ZN, Yeshita HY, Mekonnen FA: Intimate partner violence and associated factors among pregnant women attending antenatal care service in Debre Markos town health facilities, Northwest Ethiopia. PloS one 2019, 14(7):e0218722.

23.Malan M, Spedding MF, Sorsdahl K: The prevalence and predictors of intimate partner violence among pregnant women attending a midwife and obstetrics unit in the Western Cape. Glob Ment Health (Camb) 2018, 5:e18.

24.Lencha B, Ameya G, Baresa G, Minda Z, Ganfure G: Intimate partner violence and its associated factors among pregnant women in Bale Zone, Southeast Ethiopia: A cross-sectional study. PloS one 2019, 14(5):e0214962.

25.Field S, Onah M, van Heyningen T, Honikman S: Domestic and intimate partner violence among pregnant women in a low resource setting in South Africa: a facility-based, mixed methods study. BMC women's health 2018, 18(1):119.

26.Gurmu E, Endale S: Wife beating refusal among women of reproductive age in urban and rural Ethiopia. BMC International Health and Human Rights 2017, 17(1):6.

27.Wendi L. Johnson, Peggy C. Giordano, Wendy D. Manning, Monica A. Longmore: The Age-IPV Curve: Changes in Intimate Partner Violence Perpetration during Adolescence and Young Adulthood. Journal of Youth and Adolescent 2015, 44(3):708-726.

28.Alebel A, Kibret GD, Wagnew F, Tesema C, Ferede A, Petrucka P, Bobo FT, Birhanu MY, Tadesse AA, Eshetie S: Intimate partner violence and associated factors among pregnant women in Ethiopia: a systematic review and meta-analysis. Reproductive health 2018, 15(1):196.

29.Annabel Erulkar: Early Marriage, Marital Relations and Intimate Partner Violence in Ethiopia. International perspectives on sexual and reproductive health 2013, 39(1):6-13.

30.Fanuel Omondi Otieno: A Meta-analysis of the Association between Intimate Partner Violence and Age Disparity in sub-Saharan Africa University of Stellenbosch; 2017.

31.Adebowale A: Spousal age difference and associated predictors of intimate partner violence in Nigeria. BMC Public Health 2018, 18. 
32.Zegenhagen S, Ranganathan M, Buller AM: Household decision-making and its association with intimate partner violence: Examining differences in men's and women's perceptions in Uganda. SSM Popul Health 2019, 8:100442.

\section{Supplementary Files}

This is a list of supplementary files associated with this preprint. Click to download.

- STROBECrosssectionalstudy.pdf 